\title{
LOS ORÍGENES DE LA ANTROPOLOGÍA EN ESPAÑA: MADRID, CENTRO RECEPTOR DE LAS CORRIENTES DE INNOVACIÓN EUROPEAS
}

\author{
Marisa González Montero de Espinosa
}

Facultad de Medicina - Universidad de Alcalá de Henares

\section{RESUMEN}

El conocimiento del hombre en la España del siglo de las Luces estuvo condicionado por prejuicios e intolerancia, fue sometido al dictamen de la ciencia y de la religión. Los estudios anatómicos tuvieron un destacado papel convirtiéndose en un novedoso frente cientifico; sin embargo, a la cita no faltaron eruditos y divulgadores como Feijoo o Hervás y Panduro, quienes dedicaron sus reflexiones al análisis del ser humano. El marco antropológico quedaría definido si consideramos la publicación y difusión que la obra de Buffon tuvo a pesar de la censura inquisitorial.

\section{SUMMARY}

The knowledge of man in the Spain of the Enlightment was conditioned by prejudices and intolerance, was subjected to the verdict of science and religion. The anatomical studies had an outstanding role being converted in a new scientific front; however, to the appointment didn't miss erudites and propagandists like Feijoo or Hervás and Panduro, who dedicated their thinkings to the analysis of the human being. The anthropological frame would remain defined whether considered the publication and diffusion that the work of Buffon had, in spite of the inquisitorial censorship.

«Y si el hombre no se emplea en conocer lo que es, obra no como hombre, sino como bestia».

L. Hervás y Panduro, Historia de la vida del hombre, tomo I, página 2.

A pesar de que suele dibujarse el siglo XVIII como un período de efervescencia reformista en casi todos los aspectos, los estudios históricos concretos nos muestran una centuria muy distinta, hasta llegar incluso a cuestionarse la idea de que el Siglo de las Luces suponga una ruptura con respecto a las oscuras décadas precedentes. 
Ha sido Paul Hazard ${ }^{1}$ uno de los que mejor ha puesto de relieve cómo se van fraguando poco a poco desde finales del XVII los planteamientos que luego se desarrollarán en el XVIII.

Por lo pronto hay que tener siempre en cuenta que esa Ilustración está limitada a una minoría de la clase dirigente y, por debajo de ella, todo sigue igual: miseria, ignorancia y superstición, tanto en el medio rural como en el urbano, incluso - aunque en menor medida - en la propia capital, en el mismo Madrid. La España ilustrada sigue siendo pobre, atrasada, en ella reina el hambre y las epidemias hacen estragos.

Esa situación de inferioridad cultural mueve a determinadas capas intelectuales a hacer difíciles equilibrios en dos frentes complementarios: la apertura a los aires renovadores del extranjero y la lucha contra la tradición. Con respecto a la primera, se ha insistido mucho en la influencia francesa, hasta el punto de eclipsar otras nada desdeñables, como las que proceden de Inglaterra o Italia. Podemos encontrar sobradamente ejemplos de este influjo galo a lo largo del siglo, como la fundación en Madrid en 1725 del Seminario de Nobles, siguiendo la moda de Francia, o la publicación en nuestra capital del Diario de los Literatos de España (1 de Enero de 1737) siguiendo el modelo del Journal des Savants de Paris.

En el mismo proceso de asimilación de la cultura europea se encuentran los ilustrados con el otro factor antes mencionado, el peso de la tradición, representado por los sectores más conservadores de la sociedad y sobre todo por la Iglesia como institución. Los pensadores del Siglo de las Luces opinaban que la Razón debía primar sobre la Religión, en el sentido de que la libertad de conciencia debía anteponerse a la autoridad eclesiástica. A partir de estos supuestos puede verse la época dieciochesca como un período de fuertes contrastes, con tendencia a las contradicciones, en el que nos encontramos una lucha entre lo viejo y lo nuevo, lo tradicional y lo revolucionario, la Religión y la Ciencia, lo establecido y lo innovador...

Esta fiebre de reformas - pero a la postre reformas fallidas- es particularmente patente en el campo de la ciencia. Los mismos ilustrados españoles se quejaban del atraso científico de nuestro país e intentaban buscar las posibles causas; así, el escritor gaditano afincado en nuestra capital, José Cadalso, en sus Cartas Marruecas, publicadas integramente en el Correo de los Ciegos de Madrid, se lamentaba de las durísimas condiciones en que trabajaban los pocos hombres de ciencia que había dado España y afirmaba que el retraso científico «procede de la falta de protección que hallan sus profesores» y resaltaba el hecho, por todos conocido, de que el estudio de las ciencias no daba de comer ${ }^{2}$. En un sentido muy parecido se manifestaba el naturalista Félix de Azara al evaluar el conjunto de su obra: «No espero verla estima-

1 HAZARD, P. (1975), La crisis de la conciencia europea, Madrid.

2 Cf. CAdalso, J. (1984), Cartas Marruecas, carta VI, Madrid. 


\section{LOS ORÍGENES DE LA ANTROPOLOGÍA EN ESPAÑA: MADRID, CENTRO RECEPTOR}

da en este país, donde el gusto por las ciencias y, sobre todo, por la Historia Natural está absolutamente dado de lado» ${ }^{3}$.

Desde el extranjero, se enjuiciaba la situación de España en unos términos no menos duros a los que empleaban los propios españoles. Fue un artículo de Nicolás Masson de Morvilliers dedicado a España, e inserto en la Géographie Moderne obra a su vez incluida en la Enciclopédie Méthodique ${ }^{4}$ _ el que desató la polémica y las iras en nuestro país. En realidad Masson no decía nada que no hubiese sido ya dicho por otros críticos, pero sus planteamientos buscaban indisimuladamente la disputa e incluso la provocación ${ }^{5}$.

A pesar de que el propio escritor francés abría al final de su discurso una puerta a la esperanza -España, según él, parecía renacer a todos los niveles, desde el industrial al científico-, varios autores españoles, unas veces por iniciativa individual, como Cavanilles o Denina, y otras desde sectores oficiales, como J. Pablo Forner por encargo de Floridablanca, dedicaron sus mayores esfuerzos a reivindicar el buen nombre de nuestro país. Otros, en cambio, - un sector más minoritario- encabezados por Luis Cañuelo (desde las páginas del semanario matritense El Censor) reconocían parte de los defectos expuestos por Masson, con el fin explícito, en buena parte político, de luchar contra el lastre de la tradición.

Quisiéramos también aludir a otros dos factores que incidieron muy directamente sobre el cultivo de las ciencias en la España ilustrada y que tuvieron un impacto inequívocamente negativo sobre el tímido despegue científico de la Ilustración española: nos referimos a la expulsión de los jesuitas y al problema de la censura. Con respecto al primero, hay que tener en cuenta que esta congregación dominaba y acaparaba puestos claves en la enseñanza, en las Universidades, etc.; en consecuencia su expulsión supuso una peligrosa situación de vacío que otras órdenes no pudieron llenar.

El otro factor que contribuyó a retardar el arranque científico español fue, como antes mencionábamos, el ejercicio de la censura por parte de la Inquisición. La consabida cuestión acerca de en qué medida esta actividad inquisitorial pudo afectar a la ciencia española es difícil de contestar. Hay que tener en cuenta que también existió esta censura en los demás paises europeos, incluso en los que se tenían por mas «avanzados»: el famoso Emilio de Rousseau, por ejemplo, fue prohibido en La Haya,

3 Cf. Álvarez López, E. (1952), «Comentarios y anotaciones acerca de la obra de D. FÉlix DE AZARA», Miscelánea Americanista, tomo III, C.S.I.C., Madrid, p.26.

4 Esta inmensa obra tuvo gran repercusión e influencia en nuestra península. El editor galo C.J. PANCKOUKE consiguió autorización para que se publicara en castellano y gracias al impresor español Antonio Sancha comenzó a aparecer en las librerias madrileñas. Pronto la Inquisición se alzó contra ella a raíz del artículo de Nicolás Masson y fueron secuestrados unos 1.600 volúmenes de las tiendas de nuestra capital.

5 El artículo de Masson está reproducido en ERnesto y EnRique García Camarero (eds) (1970), La polémica de la ciencia española, Alianza Editorial, Madrid, pp.47-53. 
en Paris ${ }^{6}$, etc. Pero censura no equivalía exactamente a imposibilidad de que un libro fuera conocido y divulgado, ya que por ejemplo en el caso español, un buen porcentaje de la élite intelectual leía francés y podía adquirir las obras extranjeras de modo directo; aún mas, instituciones públicas en Madrid y en otras zonas españolas adquirían obras «peligrosas», a veces incluso con la anuencia de la autoridad eclesiástica, que permitía ciertas excepciones.

La otra cara de la moneda estaría constituida por los intentos minoritarios para superar esa situación y poner a España al nivel de los países europeos de su entorno. En este contexto tienen lugar una serie de tentativas de cambio que discurren básicamente por tres vías diferentes: en primer término, se crean nuevas instituciones para que cumplan la misión que las Universidades parecen incapaces de realizar; en segundo lugar, se introducen cambios sustantivos en los programas de estudios, sobre todo a nivel metodológico, promoviéndose la observación y la experimentación; por último, se ensayan diversos estímulos a la investigación, entre los que destaca la promoción del contacto de científicos españoles con extranjeros.

En estas facetas tendentes a una reconstrucción científica ocupa un papel fundamental, tal y como hemos apuntado anteriormente con algunos ejemplos, nuestra capital. Efectivamente Madrid, al igual que la mayoría de las metrópolis europeas, se convirtió en receptora de la ciencia ilustrada. Pero para eso fue primero esencial poner las bases necesarias y crear una infraestructura adecuada para poder recoger, analizar y estudiar todo lo que hasta ella llegará de los países limítrofes.

Entre las nuevas instituciones que pretenden tomar el relevo de los organismos caducos, destaca sin lugar a dudas la Sociedad Económica Matritense, fundada en 1775 bajo la dirección de don Antonio de la Quadra, aunque en realidad fue Campomanes el alma de este organismo. En su seno se fraguan las más importantes obras de prohombres ilustrados, como Cabarrús y Jovellanos ${ }^{7}$. Además, su organización y estructura se convirtió en modelo para las demás Sociedades Económicas, que se expandieron rápidamente por toda la península.

De menor transcendencia, aunque su importancia no es desdeñable, resulta la fundación de las Academias en nuestra capital. En 1714 se funda la Academia de la Lengua, en 1738 la Academia de la Historia, en 1744 la Academia de Bellas Artes de San Fernando... y un largo etcétera. Además de por las Sociedades Económicas y por las Academias, la importancia de Madrid como centro receptor de las corrientes europeas se ve favorecido por el desarrollo de la prensa que - aunque todavía no era el

\footnotetext{
6 Podemos ver la noticia de su prohibición en ambos países europeos en el periódico de Madrid Mercurio histórico y político, de Julio y Septiembre de 1762 respectivamente.

7 Una síntesis de la actividad ilustrada en el seno de la Sociedad Económica Matritense, en ABELLÁn, J.L. (1981), Historia crítica del pensamiento español, tomo III: Del Barroco a la Ilustración, Madrid, pp.741-743.
} 
termómetro de la sociedad, como en los siglos posteriores - se hizo eco de la preocupación intelectual de la época, reseñando o criticando en lugares preferentes las nuevas obras, o dando cabida a noticias sobre los pensadores y científicos del momento.

En efecto, el siglo XVIII conoce una expansión sin precedentes de todo tipo de periódicos; obviamente, la mayoría de ellos se editaban en nuestra capital, que contaba con un gran número de suscriptores. Estos rotativos abarcaban una gran variedad temática, aunque aquí haremos hincapié únicamente en los aspectos específicamente científicos. Así, el Diario de Madrid publicaba entre enero y febrero de 1789 hasta 11 artículos relativos a los adelantos científicos; el Correo de Madrid difundía 22 escritos de Física en un año (de octubre de 1787 al mismo mes del siguiente año); el Espiritu de los mejores diarios literarios que se publican en Europa, periódico bisemanal fundado a mediados de 1787 , pretendía responder a su mismo título ofreciendo una síntesis de los principales avances de la ciencia en toda Europa.

Todo esto va creando un caldo de cultivo adecuado y Madrid en particular - y el país en general - se va abriendo poco a poco a los aires del exterior, produciéndose un contacto entre científicos españoles y extranjeros desconocido hasta ese momento: viene a la metrópoli el irlandés Bowles invitado por Antonio de Ulloa; el químico francés Proust dirigió en la capital el laboratorio del rey Carlos IV; y el botánico sueco Loeffling fue enviado por Linneo al centro de la península. Aunque entre la élite intelectual no era necesaria la traducción del francés al español para ponerse en contacto con las grandes obras del momento, también se acometieron en las editoriales matritenses las traducciones de obras como la Enciclopédie Méthodique, a la que aludíamos anteriormente, o libros notables como el Spectacle de la Nature del abate Pluche que conoció dos ediciones antes de 1785 (a pesar de ser una obra en 16 tomos), o el Essai sur l'electricité des corps de Nollet.

\section{EL CASO DE LA HISTORIA NATURAL}

Esta renovación o incluso revolución científica se pone muy de manifiesto con respecto a las Ciencias Naturales, tal y como lo expresa el irlandés William Bowles. Este científico afincado en la capital se lamentaba del atraso de esta ciencia en España, a pesar de las posibilidades que ofrecía la tradición viajera y descubridora: «de los viajeros españoles modernos no hablo, porque me sería preciso dudar si han sabido que hubiese Física, según el olvido con que la han tratado»; a continuación prosigue su reflexión nombrando a unos pocos marinos y escritores que son la excepción que confirma la regla y concluye del siguiente modo: «si los que les han sucedido 
hubiesen seguido su ejemplo, hoy nos hallaríamos con tales progresos en las Ciencias Naturales, que tal vez nos pasmarían ${ }^{8}$.

Parecidas observaciones efectuaba el entonces vicedirector del Real Gabinete de Historia Natural madrileño, José Clavijo y Fajardo: «no pretendo ofender a mi nación, ni dar armas a sus émulos, dedicados casi por instinto, a censurarla», se justificaba Clavijo, sino solo constatar que respecto a «lo que otras naciones han adelantado en estas materias(...) nos hallamos nosotros atrasados»?

A pesar de todas estas lamentaciones, lo cierto es que durante el siglo XVIII tiene lugar un importante impulso en este terreno, fruto de la curiosidad que produce la Naturaleza en todos sus ámbitos, y Madrid se beneficia de eso. Prueba de ello es la creación en nuestra capital del Real Gabinete de Historia Natural ${ }^{10}$ y del Jardín Botánico de Madrid" . En los planes de estudio de las Universidades no se reflejaba sin embargo el interés por el estudio de la Naturaleza, aunque una rama emparentada en cierta medida con ella, como la Medicina, adquiría nuevos aires con el fomento de las disecciones.

Sin embargo, habría que destacar - en el campo de las Ciencias Naturales- la labor de estudiosos como Ignacio Asso y del Río en Zoología; Andrés Manuel del Río en Mineralogía; Quer, Gomez Ortega y Cavanilles desde el Jardín Botánico de la capital; Cuéllar, Pineda, Haenke y Née designados por el gobierno español para formar colecciones - en sus expediciones científicas a América - destinadas a enriquecer el Gabinete de Historia Natural. De la obra de uno de estos investigadores concretamente el Nuevo discurso de la generación de plantas, insectos, hombres y animales (1747) de Francisco García- hace Celso Arévalo un desmedido elogio afirmando que este naturalista dieciochesco descubrió la sexualidad de las plantas «antes de que Linneo la hiciese base de sus estudios botánicos» y negó la teoría de la generación espontánea «más de un siglo antes de que Pasteur con nuevos medios la aniquilase» ${ }^{12}$.

8 Cf. Bowles, G. (1789), Introducción a la Historia Natural y a la Geografía física de España, Madrid, pp.14-15.

9 Cf. Buffon (1791-1805), Historia natural, general y particular, Madrid, tomo I, pág.V, prólogo del traductor.

10) Sobre las circunstancias que concurrieron en su génesis, véase el libro de Calatayud, $\mathrm{M}^{\mathrm{a}} \mathrm{A}$. (1988), Pedro Franco Dávila y el Real Gabinete de Historia Natural, Madrid, pp. 42-56, y 91-96.

1 Sobre la creación y desarrollo de esta institución matritense puede consultarse el libro de Gredilla y Gauna (1911), Jardín Botánico de Madrid, su origen, importancia científica y relaciones internacionales, Madrid. Dicha obra es una recopilación de artículos aparecidos en la Correspondencia de España en Noviembre de 1910.

12 ARÉvalo, C. (1940) «Un biólogo español del siglo XVIII», Anales de Ciencias Naturales, C.S.I.C., Madrid, p.1. 


\section{LOS ORÍGENES DE LA ANTROPOLOGÍA EN ESPAÑA: MADRID, CENTRO RECEPTOR}

Pese a lo que exageraciones como ésta parecen sugerir, las Ciencias Naturales no estaban en España al mismo nivel de desarrollo que en otros países de la Europa Occidental. Se estaban haciendo grandes esfuerzos, entre los que caben destacar la financiación de la formación en el extranjero de destacados investigadores españoles como Carlos de Gimbernat (nombrado en 1798 vicedirector del Gabinete de Historia Natural de Madrid), mientras que - como antes mencionábamos- se fomentaba el acceso de científicos extranjeros a nuestro país, en concreto a nuestra capital.

Uno de los indicadores más interesantes del progreso de las Ciencias Naturales en Madrid, lo constituye el incremento de obras de esta índole en las bibliotecas de la capital y en las colecciones particulares de los intelectuales de la época: el Systema Naturae de Linneo se había hecho absolutamente imprescindible; casi lo mismo podía decirse de la Historia Natural de Buffon en la traducción de Clavijo; Jovellanos tenía también, entre otras, los Études de la Nature de Bernardin de Saint-Pierre, obra prohibida por la Inquisición, pero muy apreciada por el escritor español.

Los propios ilustrados, aunque la Historia Natural no estuviera en el centro de sus preocupaciones intelectuales, hicieron algunas reflexiones sobre el particular: así por ejemplo, el jesuita conquense Lorenzo Hervás y Panduro abordó la cuestión del avance de las Ciencias Naturales y terció en las grandes polémicas biológicas que apasionaban a los estudiosos de su tiempo, como la inmutabilidad de las especies que él defendía-, la cadena de los seres vivos, el eslabón perdido y el debate sobre la concepción y reproducción de la especie humana, en el que mantenía una postura epigenista ${ }^{13}$.

Pero entre ellos fue sin duda el P. Feijoo quien, de manera más continuada, reflexionó sobre los problemas que llevaba aparejado el estudio de la Naturaleza; factor nada sorprendente si consideramos su extensísimo campo de preocupación intelectual. Precisamente esa capacidad de disertar sobre los más variados temas buscando siempre el auxilio de la razón en su sentido más puro, hizo de Feijoo un símbolo, reconocido desde entonces como tal por los más diversos autores. Blanco White nos relata en páginas emocionadas lo que supuso para él enfrentarse por primera vez a las obras de Feijoo: «No sin dificultad logré permiso para probar si mi inteligencia, que hasta entonces había permanecido baldía, tenía bastante fuerza para entender y saborear a Feijoo», y continúa diciendo que «el contenido de sus páginas cayó en mi alma como las lluvias primaverales en una tierra sedienta» ${ }^{14}$. Marañón, por su parte, le juzga el creador del lenguaje científico en nuestro país ${ }^{15}$.

13 Podemos ver referencias a todas estas discusiones biológicas en los tomos I y V de la Historia de la vida del hombre, Madrid, 1789-1799.

14 Blanco White, J. (1972) Cartas de España, Madrid, pp 99-100.

15 Marañón, G. (1934), Las ideas biológicas del P. Feijoo, Madrid, pp. 89 y ss. 
«En ninguna materia hay tanta pobreza de escritores juiciosos y fieles, como en la Historia natural», nos dice el benedictino en uno de los discursos dedicados precisamente a esta disciplina y publicados en su Teatro crítico, cuyo primer tomo apareció en Madrid el 3 de Septiembre de 1726, en la imprenta de Lorenzo Francisco Mojados. Según Feijoo los relatos de los naturalistas están repletos de fantasías absolutamente increibles; en este punto el escritor español es muy crítico, censurando incluso las «ligerezas» de Aristóteles en ese aspecto. Los «modernos» por otra parte han incurrido, nos dice, en el error de «trasladar ciegamente las patrañas que dejaron escritas los antiguos».

Este discurso al que nos referimos está íntegramente dedicado a combatir los errores más comunes, más extendidos entre el vulgo, en ese terreno del estudio de la Naturaleza. Hagamos, por ser tan revelador, una sucinta relación de algunos de los numerosísimos casos que enumera y rebate Feijoo: los animales venenosos, como la víbora, no producen daño alguno al ser comidos; no hay ningún animal de vista tan penetrante que pueda atravesar los cuerpos opacos (se refería aquí Feijoo a la conocida fábula del lince). Y sigue diciendo: no responde a la verdad la creencia de que las ballenas tengan tan angosta su garganta que por ella sólo puedan penetrar peces del tamaño de la sardina; la rosa de Jericó, escribe, ni es rosa, ni es de Jericó, ni se abre la noche de Navidad; no existen lagos que formen una tempestad al arrojar en ellos una piedra; el diamante, continúa, no se ablanda, como muchos creen, con la sangre caliente del cabrito; las margaritas no se engendran del rocío... A pesar de que en este punto no se atreve a dar una respuesta absolutamente tajante, considera Feijoo «improbable» la existencia de animales fabulosos (desde el famoso unicornio al Ave Fénix...) y en todo caso rebate las propiedades mágicas que por lo general se les atribuye: la incombustibilidad de la salamandra, por ejemplo, o la mirada mortal del basilisco... ${ }^{16}$

Feijoo, al igual que la mayoría de los pensadores de su tiempo, se nos muestra como una persona preocupada por el estado cultural de la España de su época, por el bajo nivel de la enseñanza, por el anquilosamiento de las Universidades; en la «Carta sobre las causas del atraso que se padece en España en orden a las Ciencias Naturales» ${ }^{17}$, establece seis motivos para explicar el fenómeno: ignorancia de los profesores, rechazo de las novedades, aversión hacía los modernos planteamientos científicos (que son tildados de curiosidades inútiles), desconocimiento o desprecio de la filosofía de la época, la envidia - tanto a nivel personal como nacional- y en fin, el temor de que las doctrinas nuevas perjudiquen a la Religión. Efectivamente, las ciencias — sobre todo si iban acompañadas del calificativo de «nuevas»— eran con-

16 FeijOO, B. (1726-1740), Teatro crítico universal, tomo II, discurso 2, Madrid, pp.28-54

17 Esta carta está incluida en el tomo II de las Cartas eruditas y curiosas en la que por la mayor parte se continúa el designio del Teatro crítico, Madrid, 1742-60, p.215. 
sideradas peligrosas a priori; si el campo de alguna de ellas ya de por sí despertaba recelos - ipor qué investigar en un terreno en que se impone la verdad incuestionable del dogma?-, sus principios, sus métodos y sus conclusiones podían caer ampliamente en la amplia zona de lo herético. De ahí que con frecuencia, tal y como admite Sarrailh, los cultivadores de las nuevas ciencias insistan en que el campo de la Ciencia y el de la Religión son completamente diversos, y que los principios de esta última son siempre superiores a los científicos ${ }^{18}$. Da la impresión de que, si hubieran podido, los ilustrados habrían resucitado la teoría medieval de la doble verdad para salvaguardar los descubrimientos hechos por la vía experimental.

Incluso nos encontramos que hasta el propio uso del concepto de Naturaleza puede resultar sospechoso: «es muy común en nuestros filósofos, cuando se habla de los prodigios naturales» - afirma Juan Francisco de Castro- «recurrir admirando a la Naturaleza, como si ésta fuese alguna denominación digna de los elogios de que se le hace objeto». Dicho con otras palabras, lo que resulta inadmisible, según este autor, es el elogio a la Naturaleza en detrimento de su Creador: «Si la Naturaleza es inteligente, razonable, sabia, y poderosa, es el mismo Autor que la produjo, y de quien enteramente pende, que todo lo sabe, y dispone con soberano poder, e inteligencia» ${ }^{19}$.

Además, es preciso salvaguardar a toda costa el principio de la perfección de todo lo creado, y hacerlo compatible con las imperfecciones que caracterizan el estado actual del reino de la Naturaleza, lo cual da lugar a consideraciones del tipo de la de Bejarano Galavis; este escritor sostiene que Dios en un principio creó a las especies más perfectas y que después «por el poder de las causas naturales se procrearon los imperfectos». Seguidamente nos ilustra su teoría con un ejemplo: «en el principio no tuvieron Adán y Eva piojos, pulgas, chinches, ni otros insectos o animalejos que al presente nos molestan» ${ }^{20}$.

A pesar de todas estas limitaciones y cortapisas, el balance es desde luego positivo, y, poco a poco, el estudio de la Naturaleza y del hombre adelanta en la España del Siglo de las Luces. Uno de los caminos que favorece este pequeño avance es el interés hacia América y sus habitantes presente a lo largo de toda la centuria, la atracción por la riqueza y el exotismo de aquellas lejanas regiones y, en consecuencia, el deseo de conocer ese «otro» mundo inexplorado para el europeo.

\footnotetext{
18 SARrailh, J. (1957), La España ilustrada de la segunda mitad del siglo XVIII, Fondo de Cultura, México, p. 499.

19 CASTro, J.F. (1780), Dios y la Naturaleza, tomo II, Madrid, pp.154-162.

20) CF. Bejarano Galavis y Nidos, J. (1791), Sentimientos patrióticos o conversaciones cristianas que un cura de aldea verdadero amigo del país inspira a sus feligreses, tomo II, Madrid, pp.469-
} 470 . 


\section{LA CURIOSIDAD HACIA EL NUEVO MUNDO}

Los estados de Europa Occidental —en particular Francia, Inglaterra, además de España, naturalmente- pugnaban por profundizar en el conocimiento de aquellas tierras, base indispensable para desarrollar y consolidar su dominio comercial y político. No obstante, sobre todo en la segunda mitad del siglo XVIII, el interés de las potencias europeas hacia el continente americano tenía también un componente marcadamente científico, ya que uno de los objetivos esenciales de las expediciones era proporcionar la más completa información zoológica, botánica, mineralógica, geográfica, cartográfica, astronómica, económica y antropológica, ademas de la meramente política. Para poder abarcar todas estas facetas fue necesario que las dotaciones de los buques, planificadas desde Madrid, incluyeran no solo marinos, sino un conjunto de estudiosos o especialistas que garantizaran el eficaz cumplimiento de las tareas de investigación.

Uno de los principales estímuløas estos viajes hispanos era esa sed de conocimientos propia del siglo, ese afánepur estudiar y clasificar los seres vivos, la pasión por observar y analizar lo desconedo (tierras fabulosas, nuevas especies vegetales, etc.) y, por último, el deseo de recolectar todo tipo de animales, minerales, plantas, restos de seres vivos... para enviarlos al Real Gabinéte de Historia Natural de nuestra capital. Por supuesto, uno de los objetivos de estas navegaciones era entablar contacto con los habitantes del Nuevo Continente, y estudiar sus relaciones, costumbres, religión, en una palabra su forma de vida.

Para ello era necesario previamente ganarse su confianza, cosa nada fácil debido al trato inhumano que con frecuencia habían recibido los indígenas de los conquistadores. Pero la actitud de los expedicionarios ilustrados era completamente distinta, tanto en sus fines como en sus métodos, enlazando en cierto modo con los primeros viajeros e historiadores de Indias que, con sus descripciones, se convirtieron en los pioneros de los estudios etnológicos en nuestro país. La información que proporcionaron las expediciones acerca de los naturales de aquellas tierras fue la base de la que se nutrieron los grandes antropólogos del XVIII (Buffon, Blumembach, Hervás y Panduro en España) para elaborar sus teorías sobre la especie humana.

En los viajes con carácter más marcadamente antropológico estaba patente, implícita o explícitamente, una denuncia de las difíciles condiciones de subsistencia de los indígenas; indudablemente esta crítica hacia la administración española, de un tono más humanitario que estrictamente político, sería instrumentalizada después por los colonos para favorecer la independencia política de las naciones americanas.

Recordemos someramente las principales expediciones organizadas desde Madrid o protagonizadas por españoles durante el siglo XVIII. En 1735, la Academia de Ciencias de Paris nombró una comisión científica, dirigida por La Condamine, para estudiar la forma de la tierra; Luis XV solicitó la autorización y apoyo de Felipe V, 
quien no solo accedió sino que dispuso que se agregasen a este viaje Jorge Juan y Antonio de Ulloa ${ }^{21}$.

Entre las comisiones enviadas para la exacta demarcación de los límites hispanoportugueses, habría que destacar la expedición al Río de la Plata, en 1781, protagonizada por Félix de Azara; este naturalista describió todos los pueblos habitantes de aquellas zonas, ya que opinaba que la faceta antropológica era precisamente la principal y la más interesante de la descripción de un país 22 . Se detuvo también Azara en el relato de los medios empleados por los conquistadores en general y por los jesuitas en particular para reducir y someter a los indígenas, siendo muy crítico al respecto.

En el último cuarto de siglo se llevaron a cabo tres importantes expediciones botánicas. En 1777 partió una con destino a Perú y Chile, llevando como especialistas en Historia Natural a los españoles Hipólito Ruiz y José Pavón, y al francés Dombey. Nueve años más tarde tuvo lugar la que bajo el mando de José Celestino Mutis se dirigió a Nueva Granada. En 1787 salió la tercera, conducida por Martín Sessé, que llegó hasta los territorios de Nueva España, contando con los naturalistas Vicente Cervantes, José Mariano Moziño y José Maldonado. En estos tres viajes se ocuparon los expedicionarios, aunque no fuera el objetivo principal de los mismos, de la descripción de los naturales. Así Ruiz y Pavón estudiaron las costumbres de los aborígenes de Perú y Chile ${ }^{23}$, y reunieron una amplia colección etnográfica. Del mismo modo Moziño observó a los naturales de Nootka y elaboró un diccionario de su lengua ${ }^{24}$.

En los últimos quince años del periodo ilustrado tuvieron lugar cinco expediciones transcendentales. En 1785 partió la fragata Santa María de la Cabeza, al mando de Antonio de Córdoba y Lazo, hacia el estrecho de Magallanes. Esta misión, que llevaba como naturalistas a Luis Sánchez y Bartolomé de la Riva, trajo importantes noticias sobre los supuestos gigantes de la Patagonia ${ }^{25}$. Cuatro años después partió una de las más ambiciosas hacia las costas de América, Asia y Oceanía. Iba dirigida por el italiano Alejandro Malaspina y contaba con importantes especialistas en el campo de la Historia Natural (el español Antonio de Pineda, el francés Luis Née y el checo Tadeo Haenke). En su largo periplo alrededor del mundo describieron a los

\footnotetext{
21 Puede verse la labor de estos marinos españoles en sus obras: Relación histórica del viaje a la América meridional, Madrid, 1748, y Noticias secretas de América, Londres, 1826.

${ }_{22}$ Cf. AzARA, F. (1969), Viajes por la América meridional, Espasa Calpe, Madrid, col. Austral, ${ }^{\circ}$ 1402.

23 Cf. Ruiz López, H. (1931), Relación del viaje hecho a los reinos de Perí y Chile (edición de A.Barreiro), Madrid.

${ }_{24}$ Cf. Moziño, M. y SuÁrez de Figueroa (1913), Noticias de Nutka. Diccionario de la lengua de los Nutkenses y descripción del volcán de Tluxla, México.

${ }_{25}$ Cf. Relación del último viaje al estrecho de Magallanes de la fragata de S. M. Santa María de la Cabeza en los años de 1785 y 1786, Madrid, 1788.
} 
habitantes de Puerto Deseado (Argentina), archipiélago de Chiloé (Chile) ${ }^{26}$, Puerto Mulgrave (Alaska), isla de Nootka (Canadá) e isla de Vavao (Oceanía) ${ }^{27}$, además de realizar una intensísima labor de investigación y estudio en las más variadas facetas de la Historia Natural.

En 1795 y 1796 partieron dos nuevas misiones, una dirigida por Cristian y Conrad Heuland para estudiar el reino mineral de Perú y Chile; estos hermanos narraron en su diario ${ }^{28}$ noticias curiosas sobre los indígenas y recopilaron además una gran diversidad de objetos de los nativos. La otra, hacia la isla de Cuba comandada por el conde de Mopox se dedicó principalmente a estudiar y recopilar aves, minerales y plantas. Por último, en 1799, tuvo lugar el viaje de Alejandro Humboldt ${ }^{29}$ y del botánico francés Aimé Bonpland hacia las regiones equinocciales de América, en el que se hicieron importantes observaciones en el campo de la etnografía.

Basta esta pequeña referencia, para poder afirmar sin género de dudas que las expediciones científicas españolas - constituidas por estudiosos o especialistas que garantizaron el eficaz cumplimiento de las tareas de investigación - incentivaron el desarrollo de un gran número de disciplinas científicas, entre las que la Antropología ocupaba, como no podía ser menos, un lugar fundamental.

\section{EL INTERÉS POR LA ANTROPOLOGÍA}

La dicotomía dieciochesca entre Religión y Ciencia, se pone muy de manifiesto en el caso del estudio del hombre. Pero antes de adentrarnos en ese campo deberíamos plantearnos una cuestión importantísima: ¿puede realmente hablarse de Antropología en la España de la Ilustración? No, si seguimos un criterio riguroso; pero, por otro lado, si nos quedáramos en esa negativa sin matices estaríamos distorsionando la realidad casi al mismo nivel que si nos empeñáramos en convertir en antropólogos a todos los ilustrados que dedican un par de páginas a la cuestión del hombre.

El conocimiento del hombre real — no el que dicta la Religión- avanza en el Siglo de las Luces en esa España lastrada por los prejuicios y la intolerancia. Uno de los frentes de ese avance vendría dado por el progreso de los estudios anatómicos ${ }^{30}$;

\footnotetext{
26 Puede verse la descripción que hicieron de estos aborígenes argentinos y chilenos en González Montero de Espinosa, M. (1992) La Ilustración y el hombre americano. Descripciones etnológicas de la expedición Malaspina, CSIC, Madrid.

27 Cf. Novo y Colson, P. (1885) Viaje político y científico alrededor del mundo por las corbetas "Descubierta y Atrevida", Madrid.

28 Véase Heuland, C. (1929), El viaje científico de Conrado y Cristian Heuland a Chile y Perí (edición A.Barreiro), Madrid.

29 Cf. su diario titulado Del Orinoco al Amazonas, Barcelona, 1982.

30) Cf. Ortiz Barroso, J. (1739), La anatomía, luciente antorcha. Sevilla.
} 
pero también hemos de señalar que los principales eruditos, divulgadores o ilustrados españoles — como Feijoo y Hervás y Panduro, por señalar los más destacadosdedicaban parte de sus reflexiones a analizar al ser humano. A todo ello habría que añadir el conocimiento de la obra de Buffon, cuyos trabajos se publicaron en Madrid y sortearon casi milagrosamente las barreras de la censura inquisitorial.

\section{Feijoo y el estudio del hombre}

Feijoo se aproxima a los temas antropológicos con el mismo espíritu racionalista y desmitificador que acompaña a toda su obra; en sus Cartas eruditas y curiosas publicadas en Madrid, señala las características diferenciales entre hombres y brutos y entre el cerebro humano y el de los animales ${ }^{31}$ con afán de refutar creencias vulgares, fantasías y supersticiones. En su Teatro crítico —editado también en nuestra capital - trata el color negro de los etíopes que atribuye al clima de la región en que viven y combate la hipótesis - muy extendida en determinados ambientes científicos de la época- acerca de una supuesta degradación o deterioro de la especie huma$\mathrm{na}^{32}$; en esta misma obra sostiene que el entendimiento de las mujeres no es inferior al de los hombres, y que el llamado sexo débil no es imperfecto ni monstruoso: ya que las menstruaciones femeninas, dice, no tienen la ponzoña que muchos les atribuyen, pues ni esterilizan los campos ni hacen rabiar a los brutos.

Precisamente, una parte importante de sus escritos está dedicado a negar que existan o hayan existido seres monstruosos: hombres con cabezas caninas, con ojos en el pecho, con pies descomunales, etc. Incluso en varias partes de su Teatro crítico se niega a aceptar la creencia, todavía más extendida, de que los huesos encontrados en diversas excavaciones en España y América pertenezcan a seres humanos gigantescos. En su afán desmitificador llega a afirmar que las osamentas de algunos santos, considerados popularmente gigantes, caso de ser analizadas científicamente, mostrarían bien a las claras su parecido con las de los hombres del siglo XVIII.

El erudito orensano estudió diversos aspectos antropológicos que preocupaban a las mentes más lúcidas de la época como la diversidad mental (cultural) entre los hombres de las diversas naciones del globo ${ }^{33}$, que enfocó con realismo y espíritu abierto; en cierto modo también puede inscribirse en ese marco sus consideraciones sobre los españoles y sus relaciones con otros pueblos (por ejemplo, la «antipatía de

\footnotetext{
31 Puede verse las diferencias entre hombres y brutos en Cartas eruditas y curiosas..., op. cit., tomo $V$, carta $2^{\mathrm{a}}, \mathrm{n}^{\mathrm{o}} 19$ y entre el cerebro del hombre y de los animales en la carta $6^{\mathrm{a}}, \mathrm{n}^{\mathrm{o}} 3$ del mismo volumen.

32 La referencia al color se encuentra en el Teatro crítico, opus cit., tomo VII, discurso $3^{\circ}$ y la degeneración del hombre en el tomo I.

3.3 Ibidem, tomo II, discurso 15. 
los españoles a los franceses»), sus reflexiones sobre el sentimiento nacional o sus críticas hacia determinadas tradiciones fuertemente enraizadas en el pueblo español (sobre todo las que se basan en pretendidos hechos milagrosos, como el famoso «Toro de San Marcos» de Almendralejo, en Badajoz). En esto, como en tantas otras cosas, Feijoo no se muestra como un radical que dude de la existencia de milagros, sino como un racionalista moderado que intenta circunscribirlos a unos límites muy precisos.

Terció también el escritor español en el debate sobre el poblamiento de Améri$\mathrm{ca}^{34}$, optando por una solución de compromiso entre las diferentes hipótesis acerca de cómo había podido llegar el hombre a tan lejanas tierras; para él «es ocioso buscar en los mapas el rumbo» dado que la superficie del globo debía haber cambiado muchísimo desde entonces ${ }^{35}$. En esta misma obra (tomos II y IV) analiza las cualidades de los indios americanos, sosteniendo que son de nuestra misma especie, e incluso que los criollos son de mayor viveza y agilidad intelectual que los españoles. Estas y otras defensas de la dignidad de los hombres del Nuevo Continente hicieron que Feijoo fuera muy criticado por quienes, como Corneille de Pauw, hicieron de sus obras un sistemático ataque a los americanos como reafirmación de la ya tibiamente cuestionada perspectiva eurocéntrica.

A pesar de que el tema del hombre era uno de los que ampliamente abordó Feijoo, no se puede presentar al benedictino español volcado hacia la Antropología como hace Cerra Suárez en su obra Las ideas antropológicas de Feijoo. Este autor basa sus argumentaciones en las ideas del ilustrado sobre la variabilidad de las especies, la generación espontánea, la herencia, reproducción, etc. Desde nuestro punto de vista, todos estos temas eran motivo de controversia en la época, y el clérigo hispano se limitó a exponer sus opiniones al respecto. Como en la época ilustrada se despertó el interés hacia el hombre, Feijoo abordó el tema en algunos de sus escritos, pero sin que ello supusiera - como afirma Cerra Suárez ${ }^{36}$ - que el pensador dieciochesco diera primacía a la antropología biológica sobre la filosófica y cultural. En definitiva, consideramos que no puede llamarse antropólogo a Feijoo, por más que se amplíe el concepto; el ilustrado español no pasó de ser un curioso, divulgador de gran cantidad de temas, entre los cuales estaban los relativos a la Naturaleza y al hombre.

\footnotetext{
34 Véase una pequeña aproximación a esta polémica y en general a la visión que tenían los ilustrados españoles de América y sus habitantes en González Montero de Espinosa, M. (1992).

35 Cf. FEIJO, B. (1726-1740), tomo V, pp.320-350.

36 Cf. Cerra SuÁrez (1986), Las ideas antropológicas de Feijoo. I: La génesis del hombre, Oviedo, p. 382.
} 


\section{Hervás y Panduro abre el camino a la antropología española}

Analicemos ahora con profundidad los estudios antropológicos de Lorenzo Hervás y Panduro; este jesuita conquense escribió acerca de los más variados asuntos, lo mismo reflexionó sobre las Matemáticas que sobre la Filología, Teología, Filosofía, Geografía o Pedagogía. Entre su extensa producción nos interesa destacar aquí los escritos que tienen como protagonista al ser humano: la Historia de la vida del hombre y el Hombre físico que, por supuesto, fueron publicados - en su traducción al castellano, dado que originalmente fueron escritos en italiano- en nuestra capital. En ambas puede verse claramente la importancia que tiene para él el estudio de nuestra especie: «Fábrica admirable del cuerpo humano: su consideracion es útil a todo estudio, sea en lo físico, sea en lo moral», titula uno de sus discursos ${ }^{37}$. La edición española de la primera de las obras mencionadas consta de 7 tomos, fue publicada en Madrid a lo largo de 10 años, entre 1789 y 1799, y sufrió — sólo una parte de ella- los rigores propios de la censura ${ }^{38}$.

A pesar de ser poco conocida en la España de su época, constituye el tratado más completo que se escribió sobre el hombre en la Europa ilustrada; estudia al ser humano desde gran número de perspectivas y analiza sus etapas vitales: concepción, nacimiento e infancia - en el primer tomo-, juventud —en el segundo, tercero y cuarto-, madurez -en el quinto y sexto-y, por último, la vejez —en el séptimo-. En el volumen quinto de esta magna obra defiende con calor la tesis de que el hombre es igual en todos los lugares del mundo, siendo las diferencias externas, sólo meros accidentes; esta idea de la igualdad entre los seres humanos era inusual para la época, dada la extendida creencia, incluso entre los científicos, de la inferioridad del aborigen americano respecto al europeo.

El abate español muestra una hipervaloración del hombre, con una exaltación reiterada incluso de su naturaleza material. Así, aparecen en su Historia del vida del hombre encabezamientos como «Excelencia del hombre por su perfección corporal» o «Figura y hermosura corporal del hombre: grandeza, proporción y perfección del cuerpo humano» ${ }^{39}$. Estudió los caracteres distintivos de nuestra especie, o sea, lo que hoy Ilamamos Antropología Física; esto podemos observarlo, por ejemplo, cuando analiza las diferencias físicas entre hombres y mujeres o cuando afirma que la pleni-

37 HeRvás y PANDURo, L. (1800), El hombre físico o anatomia humana física-filosófica, Madrid, tomo I, p.7.

38 Puede verse en el Archivo Histórico Nacional de Madrid, sección inquisición, alegaciones fiscales, leg. $3725 n^{\circ} 268$ y $4483 n^{\circ} 5$, el expediente de calificación, delación y censura del primer tomo de la Historia de la vida del hombre.

39) Estos dos tratados estan recogidos y reproducidos en González Montero de Espinosa, M. (1994), Lorenzo Hervás y Panduro, el gran olvidado de la Ilustración española, Madrid. 
tud del cuerpo humano llega a los 28 años en el varón y un poco antes en el mal llamado sexo débil.

Hervás, basándose en los estudios artísticos y en los experimentos anatómicos del momento, estableció una serie de criterios sobre la relación entre las distintas regiones del cuerpo, las proporciones humanas y las medidas de las diferentes partes del hombre ${ }^{40}$. Cuestiones como la estatura, el color de la piel y sus posibles causas, la unidad o diversidad de la especie humana y la constitución anatómica, tampoco pasaron desapercibidas para él, que llegó incluso a plantearse la cuestión de la «simetría maravillosa» del cuerpo, estableciendo el centro de gravedad en función de la postura del individuo. De la minuciosidad de las proporciones a la descripción casi poética del cuerpo humano, nada escapó a la curiosidad del jesuita español: incluso hizo incursiones en los nacientes estudios de craneología para hallar las causas de mudez y sordera.

Cabe considerar sin exageración que los estudios antropológicos de Hervás fueron tan completos como profundos y originales, y desde luego resultan sorprendentes para el medio y la época que le tocó vivir. En la búsqueda de un mejor conocimiento del hombre, analizó la diversidad de temperamentos y las diferentes costumbres de los grupos humanos, esquematizando también sus causas: leyes, espíritu de las religiones y educación civil de cada país. Todos estos planteamientos, para ser valorados en su justa medida, han de ser situados en el contexto de un medio cultural baldío, dominado por la intolerancia religiosa - que miraba con lupa toda disquisición sobre la naturaleza humana-, y en un país con un atraso científico notable en relación con sus vecinos europeos.

Por todo ello es más sorprendente que la obra de Hervás resista la comparación con las grandes figuras de la época: ni siquiera Buffon, por ejemplo, examinó con tanta precisión y detenimiento al ser humano, al que dedicó tres tomos de su Historia natural general y particular; en ellos el naturalista galo se ocupó de las edades, los sentidos y las variedades de la especie humana, pero desdeñó otras cuestiones, como el examen de las proporciones, puesto que en definitiva no hay que olvidar que para el científico francés el estudio del hombre era una parte importante, pero secundaria en el conjunto de su obra. En cambio, para Hervás, pese a su dedicación a otras parcelas del saber, el ser humano constituye un punto central de reflexión, como muestra el hecho de que lo estudiara desde todas las perspectivas posibles y que incluso elaborara un diccionario de Anatomía que incluyó al final del segundo tomo del Hombre físico.

40 Hervás y PAnduro, L. (1789-1799), Historia de la vida del hombre, Madrid, t.V. 
Sin embargo, en contraposición a Buffon y otras figuras ilustradas, el español ha sido ignorado por propios y extraños ${ }^{41}$; sus escritos antropológicos, por ejemplo, han permanecido practicamente desconocidos en nuestro país, a pesar de que un examen detenido de los mismos nos lleva a comprender que estamos ante el más importante autor en este campo de la España ilustrada; más aún no sería exagerado darle el título de primer antropólogo español y padre de los estudios antropológicos en nuestro país.

\section{La repercusión de Buffon en nuestro país}

Como la importancia de Buffon en la historia de la Antropología no necesita ser subrayada, nos limitaremos a señalar cuál era el grado de conocimiento que se tenía en Madrid en particular - y en España en general- de su obra, haciendo las referencias indispensables a las novedades metodológicas o de contenido que suponían las investigaciones buffonianas.

Obviamente Buffon no puede ser considerado como antropólogo en sentido estricto, dado que sus escritos sobre el hombre son sólo una parte de su magna obra, difícil de deslindar del resto de los discursos sobre el reino animal o sobre la Naturaleza en general. Pero en contrapartida también hay que recordar que Buffon apenas prestó atención a las plantas o animales inferiores; que, al contrario de Linneo, describió al hombre con todo lujo de detalles, que se ocupó de las variedades de la especie humana, que estableció las influencias del medio físico sobre los rasgos característicos de las razas, etc., razones que han llevado a Comas a considerarlo «precursor de la Antropología física» ${ }^{42}$.

La obra de Buffon no es, pese a lo que a primera vista parece, homogénea, quizás a causa de su confesada aversión - ¿rechazo a Linneo?-, a la sistematización rigurosa. Esta característica, unida a la vastedad de su campo de estudio, propició la aparición de diversas traducciones de parcelas de su obra con los títulos más variados.

En 1773 se publicaban en Madrid dos tomos de la Historia Natural del hombre, en traducción castellana de D. Alonso Ruiz de la Peña. Los títulos, como era muy propio de la época, no reflejaban sino muy parcialmente el contenido de la obra: así, en este caso, aparecían en el tomo primero unas amplias consideraciones sobre la formación de animales y vegetales ${ }^{43}$; pero el hecho mismo de que se publicaran las

\footnotetext{
41 Una excepción a la norma es el libro de Grangel, LuIS S. (1968), Humanismo y medicina, Seminario de $\mathrm{H}^{\mathrm{a}}$ de la Medicina Española, Salamanca.

42 Cf. Comas, J. (1958), «Buffon, 1707-1788, precursor de la Antropología física», Cuadernos del Instituto de Historia, serie antropológica $n^{\circ} 4$, Universidad Nacional Autónoma de México, México.

43 Buffon (1791-1805), tomo I, pp.322-333.
} 
investigaciones buffonianas referentes al hombre $-\mathrm{y}$ con ese significativo título- es exponente de la importancia que en esta materia se le empezaba a dar en España a los estudios antropológicos de Buffon. Máxime cuando en este campo, más que en ningún otro, se incurría en el riesgo de tropezar con el dogma; de hecho, el propio traductor, según reconocía en el prólogo, se había autocensurado: «nos ha parecido conveniente cercenar en esta traducción tal cual trozo del original, cuya sustancia hemos compendiado no obstante, del modo más decente que nos ha sido posible, y se reduce a unas cinco o seis hojas todo cuanto se ha suprimido» ${ }^{44}$.

Recordemos que en esta obra se adentraba Buffon, por ejemplo, en el resbaladizo terreno de la distinción entre el alma humana y la de los animales: ésta, decía, debe ser única para toda la especie, en contraposición al alma humana individual, específica de cada uno; a su vez, tanto en el hombre como en el animal, Buffon distinguía materia y alma. El principio espiritual, decía el naturalista, aparece y se desarrolla en el ser humano más tarde que el elemento material; afirmaciones como ésta y en general toda la «filosofía de la Naturaleza» de Buffon, rebajaban la supuesta dignidad del hombre como «rey de la creación», puesto que incluso el animal era superior al hombre en determinados aspectos ${ }^{45}$.

Insistía además el científico francés en la gran influencia del medio social y cultural sobre el ser humano: «un hombre criado siempre en una selva nos parecería realmente el animal más singular, más desconocido y más difícil de describir» ${ }^{46}$. De ahí podría deducirse que la única diferencia entre el «salvaje» y el «civilizado» estaba en que este último había podido acceder a las ventajas de la educación.

En 1791 comenzaba a publicarse también en nuestra capital la que sería versión clásica de la obra buffoniana: la traducción de Clavijo y Fajardo en 31 volúmenes, respetando la distribución que había hecho de su obra el propio autor, e incluso con las adiciones, notas y correcciones posteriores. El propio traductor - vicedirector del Real Gabinete de Historia Natural de Madrid - dejó constancia de la satisfacción que le produjo la labor realizada ${ }^{47}$, y otros especialistas se pronunciaron en el mismo sentido ${ }^{48}$, tal era el esmero que puso en la tarea.

Curiosamente, esta obra no encontró el más mínimo problema con la censura, como puede verse en la contestación de la consulta que sobre su contenido hizo a

\footnotetext{
44 Ibidem, Prólogo del traductor.

45 Cf. Deprun, «Filosofías y problemática de las luces», en Belaval, Y. (dir.) (1976), Racionalismo, Empirismo, Ilustración, tomo VI de la Historia de la Filosofía, Madrid, pp.298-299.

46 Véase Buffon (1791-1805), tomo II, p.279.

47 Cf. Barreiro, A. (1944), El Museo Nacional de Ciencias Naturales, Madrid, p.26.

48 «Gabinete», leg. 4, carp. 2, 1785, Museo de Ciencias Naturales de Madrid: Carta del Marqués de Montehermoso a Dávila.
} 
Pedro Dávila el escribano de Cámara de S.M., D. Pedro Escolano de Arrieta ${ }^{49}$. Sin embargo, lo cierto es que la obra contenía afirmaciones difícilmente defendibles desde la ortodoxia católica; Buffon hacía hincapié en la diversidad —en múltiples sentidos - de la especie humana, poniéndola en relación con las zonas climáticas, por ejemplo, lo cual podía tener una interpretación, como dice Duchet ${ }^{50}$, más amplia que la meramente física: el fundamento moral único para todos los hombres podía caer por su base; pero sobre todo, Buffon presentaba al hombre explícitamente como un animal más, afirmando que al analizar seriamente la Naturaleza se observa una verdad, quizás vergonzosa para el hombre, que «le obliga a que él mismo se coloque en la clase de los animales, a los cuales se parece en todo lo que tiene de material...» ${ }^{51}$.

Lo cierto es que, pese a todo, la obra de Buffon pasó las barreras establecidas y pudo circular libremente: ya no serían necesarias más ediciones importadas semiclandestinamente de Francia; por otro lado, la versión preparada por Clavijo se impuso como modélica a defensores y detractores ${ }^{52}$. Todo ello propició que los planteamientos buffonianos fuesen ampliamente conocidos en los círculos ilustrados; veamos algunos testimonios acerca de la gran difusión que alcanzó en España la obra del naturalista francés.

En 1797 se editaba en Madrid la traducción de la biografía de Buffon que había aparecido en París veinte años antes; contenía este volumen también su Discurso de ingreso en la Academia francesa, y el elogio que a su muerte pronunció su discípulo, el Conde de La Cepéde, entre otros textos ${ }^{53}$, algunos de ellos mutilados en su versión española por ser críticos con la labor realizada por nuestro país en el Nuevo Continente. En las dos primeras páginas del prólogo de La vida del Conde de Buffon aludía el traductor a «la general aceptación, que con tanta justicia, ha merecido en España» la Historia Natural de Buffon, hasta el punto de que esos volúmenes «andan en manos de todos, sin exceptuar el bello sexo que los maneja con gusto y deleite». Por las mismas fechas, D. Tiburcio Maquietra traducía la obra francesa Génie de $\mathrm{Mr}$. Buffon con el título de Espiritu del Conde de Buffon. Por su parte, el traductor de la

\footnotetext{
49 Véase «Gabinete», Caja grande $n^{\circ} 2$, Carpeta $n^{\circ} 3$, Copiador de cartas $n^{\circ} 18$, Museo de Ciencias Naturales de Madrid.

5) Duchet, M. (1975), Antropología e Historia en el Siglo de las Luces, Buenos Aires, 1975, p.215.

51 Cf. Buffon (1791-1805), tomo I, p.10

52 Véase por ejemplo el prólogo que escribe el traductor al español de las Conversaciones de un padre con sus hijos sobre la Historia Natural de Dubroca, Madrid, 1802-1803 (pág. XI). Muchos años después, el propio Menéndez Pelayo en su Historia de los Heterodoxos españoles (Madrid, 1965, tomo V, pág. 298) se refería a la traducción de Clavijo en términos elogiosos: «la tradujo con gran pureza de lengua, de tal modo, que aún hoy sirve de modelo».

5.3 Cf. Vida del Conde de Buffon, Madrid, 1797.
} 
obra de J. F. Dubroca Conversaciones de un padre con sus hijos sobre la Historia Natural citaba profusamente a Buffon en el prólogo recomendando a los lectores la Historia Natural en versión de Clavijo ${ }^{54}$. Las obras de Buffon desplazaron en España a las de Pluche y Nollet; se prepararon extractos de sus escritos para que sirvieran de manuales en los más avanzados centros de estudios, como el Seminario de Vergara. La huella de Buffon es reconocible en los estudios de algunos ilustrados de finales del XVIII. Buffon se convirtió para muchos en la autoridad suprema en el campo de la Historia Natural; decía por ejemplo Clavijo: «puede aplicarse al Conde de Buffon lo mismo que él dice de Plinio, esto es, que no solamente sabe lo que se puede saber, sino que posee aquella facilidad y modo de pensar que multiplica la ciencia» ${ }^{55}$.

Muchos compartían esta caracterización del sabio francés, pero no todos. Para comprender adecuadamente lo que significaban las aportaciones buffonianas en el pobre panorama intelectual español, hasta qué punto sus concepciones, su planteamiento, su enfoque, su metodología, chocaba a muchos estudiosos hispanos, nada mejor que exponer los presupuestos de una de las obras sobre la Historia Natural más importantes a finales del siglo XVIII, la de Juan Francisco de Castro. La Naturaleza, dice el autor, es una máquina perfecta; con esta premisa como punto de partida examina Castro las aparentes imperfecciones de algunos animales descritos por Buffon, como el «ahí» y el «unau»; para aquél las descripciones del francés son erradas y absurdas: «si sobre estos animales, que llamamos perezosos, hacemos las convenientes reflexiones, encontraremos que su condición es no menos natural y cómoda a ellos mismos, como es la suya a otras especies» ${ }^{56}$.

A pesar de las resistencias conservadoras, Buffon terminó imponiéndose en los círculos ilustrados madrileños, como no podía ser menos; se seguían editando parte de sus obras con títulos diversos y a menudo pintorescos: así, a finales del XIX (París, 1872), aparecía El Buffon de las familias, en traducción de F. Corona Bustamante, según una selección de Augusto Dubois ${ }^{57}$; o El pequeño Buffon (Barcelona, 1893), un compendio de Historia Natural para niños que era la traducción de una obra francesa preparada por el célebre literato $\mathrm{Jacob}^{58}$.

\footnotetext{
54 Véase págs. VI-IX, y siguientes.

55 Buffon (1791-1805), Prólogo, tomo I, pp.LVII-LVIII.

56 Cf. CASTRO, J.F. (1780), tomo I, pp.72-106.

57 Advertía el traductor en el prólogo que la Historia natural de los animales que se incluía en esa edición había sido traducida al catellano tantas veces -realizándose extractos varios- que se había desfigurado el texto original de Buffon.

58 El elogio que en el Prólogo se hace de Buffon - un siglo después de su muerte- viene a ser practicamente idéntico a los homenajes que, como hemos visto, se le tributan en las postrimerias del XVIII: «Dotado de una penetración nobilísima, animado de un entusiasmo ferviente por la poesía de la
} 


\section{LOS ORÍGENES DE LA ANTROPOLOGÍA EN ESPAÑA: MADRID, CENTRO RECEPTOR}

Ya ha quedado claro que con Buffon se inicia el conocimiento del hombre como especie, pero, dentro de esta preocupación por el ser humano, ocupa un papel importante el estudio de las razas. Es en este punto donde aparece la vinculación entre la obra buffoniana y los viajes científicos, y ello en un doble sentido: por un lado, Buffon fue sin duda el hombre de su siglo que mejor supo nutrirse de las observaciones antropológicas de los viajéros; por otra parte, el prestigio de la obra buffoniana era en España tan grande que los viajeros de algunas expediciones tuvieron buen cuidado de estudiar y copiar, antes del viaje, la parte de la obra de Buffon referente al hombre ${ }^{59}$. Y todo ello sin olvidar, como apunta Sánchez Blanco ${ }^{60}$, que la repercusión en España de la obra buffoniana no se limitó al ámbito estrictamente científico, sino que afectó también a la divulgación, es decir, estaba «al alcance del gran público».

En definitiva, como hemos podido ver a lo largo de estas pocas páginas, todo el pensamiento ilustrado está atravesado por el conflicto entre Ciencia y Religión; esta lucha afecta, como no podía ser menos, al estudio del hombre. Sin embargo, el conocimiento del ser humano atrae a estudiosos muy diversos, que abarca desde los simples curiosos a lo que hoy llamaríamos auténticos científicos, pasando por clérigos, escritores y viajeros que consiguieron poner las bases para el desarrollo de una auténtica Antropología Biológica. En todo este puzzle tiene un gran protagonismo Madrid, que recibe las benefactoras influencias de Europa y acoge a todos aquellos ilustrados que pretenden llevar a nuestro país al nivel cultural que le corresponde.

Natura, empleó su estilo literario fácil, claro y elegante en dar á conocer las maravillas que Dios ha creado(...)».

59 En el Museo de Ciencias Naturales de Madrid («Expediciones», Caja Grande, $n^{\circ} 3$, carpeta ${ }^{\circ}$ 13), hemos hallado una copia de las Variedades de la especie humana de Buffon, que puede ser atribuido a Antonio de Pineda, que iba como naturalista en el viaje alrededor del mundo dirigido por Alejandro Malaspina.

61) SÁNChez BlanCo, F. (1987), «La repercusión en España de la Historia Natural del Hombre del Conde de Buffon», Asclepio, vol. XXXIX, Madrid, p.89. 